\title{
Greenhouse gas reduction potential by producing electricity from biogas engine waste heat using organic Rankine cycle
}

\author{
A. Uusitalo ${ }^{a^{*}}$, V. Uusitalo ${ }^{b}$, A. Grönman ${ }^{\mathrm{a}}$, M. Luoranen ${ }^{\mathrm{b}}$, A. Jaatinen-Värri ${ }^{\mathrm{a}}$ \\ ${ }^{a}$ Lappeenranta University of Technology, School of Energy Systems, Laboratory of Fluid \\ Dynamics. P.O. Box 20, 53851, Lappeenranta, Finland \\ ${ }^{\mathrm{b}}$ Lappeenranta University of Technology, School of Energy Systems, Laboratory of \\ Environmental Technology. P.O. Box 20, 53851, Lappeenranta, Finland \\ * Corresponding Author. Present address: Lappeenranta University of Technology, P.O. Box \\ 20, 53851 Lappeenranta, Finland. Tel.: +358 40583 7741, E-mail: antti.uusitalo@ lut.fi
}

\begin{abstract}
Organic Rankine cycles have been identified as a suitable technological option for converting low-grade heat into electricity with relatively high efficiency, and the organic Rankine cycle technology has been successfully implemented in different power production systems and in recovering heat in industrial processes. This paper studies the greenhouse gas emission reduction potential by using organic Rankine cycles for recovering exhaust gas heat of biogas engines. The study concentrates especially on the biogas engine power plants in Europe. Life cycle assessment methods are used and various waste heat utilization scenarios are compared. According to the results, greenhouse gas emissions can be reduced significantly if the thermal energy of the exhaust gases, otherwise lost in the process as waste heat, is utilized for additional electricity production by means of organic Rankine cycle. However, there may already be use for the exhaust gas heat in biogas plants in the form of heat power. In these cases, the use of organic Rankine cycle does not necessarily lead to greenhouse gas emission reductions. The results also indicate, that the working fluid leakages and production as well as the organic Rankine cycle construction materials and production have only marginal effects on the results from greenhouse gas perspective.
\end{abstract}

Keywords: Organic Rankine Cycle, Waste Heat Recovery, Life Cycle Assessment, Greenhouse Gas Emissions

\begin{tabular}{ll}
\multicolumn{2}{l}{ Abbreviations } \\
$\mathrm{CO}_{2}$ & carbon dioxide \\
$\mathrm{CH}_{4}$ & methane \\
$\mathrm{CHP}$ & combined heat and power \\
$\mathrm{GHG}$ & greenhouse gas \\
$\mathrm{ISO}$ & International Organization for Standardization \\
LCA & life cycle assessment \\
LUT & Lappeenranta University of Technology \\
$\mathrm{NG}$ & natural gas \\
$\mathrm{N}_{2} \mathrm{O}$ & nitrous oxide \\
$\mathrm{ORC}$ & organic Rankine cycle
\end{tabular}




\section{Introduction}

Global warming due to increasing greenhouse gas (GHG) emissions is one of the greatest challenges humankind is facing. Approximately $60 \%$ of GHG emissions from human activities are related to energy production (World Resource Institute 2009). This has led to the search for more environmentally friendly energy production methods. The dominant energy production method globally is combustion, which usually leads to relatively low electricity production efficiency. For example, the electrical efficiency is $30-40 \%$ for reciprocating engine power plants (ASUE, 2011) and 20-40\% for gas turbines (ASUE 2006). The remaining heat is only utilized in some applications. Thus, if the waste heat could be converted into additional electricity the primary energy needs of the electricity production can be reduced significantly. In general, several aspects should be considered while choosing the method for waste heat utilization. Walsh and Thornley (2012 (1)) have concluded that the main barriers in utilizing low grade heat in the process industry are the cost, return on investment, and technology performance. They recommended that the energy, life-cycle and techno-economic analysis could be combined in order to identify the most promising options for waste heat recovery in different process industries.

This paper investigates the waste heat utilization in biogas engine power plants by means of the organic Rankine cycle (ORC). ORC technology is suitable for converting low grade heat into electricity, and commercial ORC power plants are available for different power scales and applications (Tchanche et al. 2011; Colonna et al., 2015). The conventional steam Rankine power plants are widely used technology in large-scale power production. The use of water as the working fluid in the cycle is an optimal solution in many cases since water is widely available, entails high thermal and chemical stability, and is non-flammable. However, if the power output of the cycle is low $(\approx P<1 \mathrm{MW})$ or the temperature level of the process is low $\left(\approx T<300^{\circ} \mathrm{C}\right.$ ) an ORC is often favored instead of a steam Rankine due to the technical difficulties related to the low boiling pressure level of steam at low temperature levels and difficulties in the expander design with steam (Colonna et al., 2015). ORC processes are based on the use of organic working fluids with a relatively low boiling temperature at reasonable pressure. The relatively low boiling point of organic fluids and the freedom in the working fluid selection enables the utilization of low-grade heat sources which would otherwise be technically or economically very difficult to utilize for electricity production. Another unique feature of ORC power systems is that the technology is in principle applicable for any external heat source (Colonna et al., (2015). Therefore, there is significant potential for ORC use globally in different heat recovery applications (Colonna et al., 2015).

In ORC processes the working fluid circulates in a closed system and the power production is based on the phase change of the working fluid from liquid to vapor. A process flow diagram and the main components of a simple ORC are illustrated in Figure 1. The ORC process can be generally divided in the following stages: 1) increasing the pressure of the liquid working fluid in the feed pump, 2) preheating the working fluid in the recuperator, 3) preheating, evaporating and superheating the fluid in the evaporator, 4) working fluid vapor expansion in the turbine from high pressure to low pressure, 5) removal of superheating in the recuperator and in the condenser, and 6) condensation of the low pressure vapor to liquid form in the condenser. 


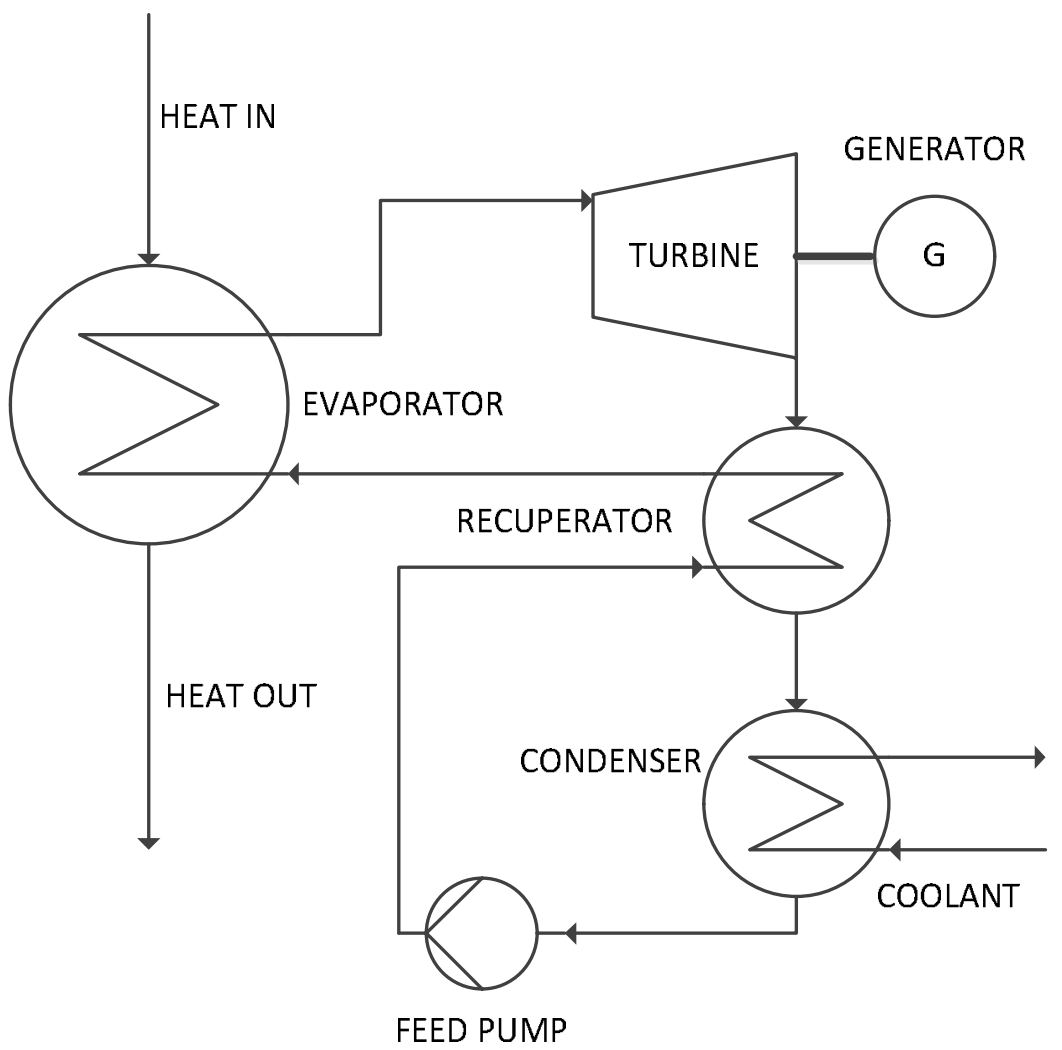

FIGURE 1. Process flow diagram and the main components of an ORC process.

Commercial ORC power systems implement different technical solutions for the expander and cycle configuration and use different types of organic working fluids e.g. hydrocarbons, siloxanes, or fluorocarbons (Tchanche et al., 2011; Colonna et al., 2015). The most important applications for ORC power systems, cycle configuration options, and important design aspects are generally presented and discussed by Colonna et al. (2015). The number of ORC power systems suitable for different power levels and different applications has been increasing significantly in recent years, mainly due to the flexibility and high conversion efficiency in low power range applications (Colonna et al., 2015). ORC has been considered applicable to waste heat recovery especially with non-centralized electricity production plants such as in reciprocating engine power plants and marine diesel engines (e.g. Bombarda et al., 2010; Uusitalo et al., 2014(1)) and in heat recovery from gas turbine applications (e.g. Invernizzi et al., 2007; Chacartegui et al., 2009). A recent patent landscape analysis for different technologies for recovering waste heat from internal combustion engines highlighted that there has been a rapid growth in the number of patent filings related to ORC in the past 5 to 10 years, which indicates a strong interest towards the ORC technology in the industrial sector (Karvonen et al., 2015).

Gas engines and gas turbines are developed to produce electricity from gaseous fuels, such as natural gas (NG), landfill gas and biogas. They are commonly located next to or at landfills, waste water treatment plants and biogas plants where in some cases the utilization of waste 
heat as heat power is not feasible or there simply is no use for heat. In these applications, ORC could be an attractive technical option for utilizing waste heat of the engines in additional electricity production and thus increasing the overall performance of engine power plants and lowering the emissions. The results of previous numerical studies (e.g. Bombarda et al., 2010; Vaja and Gambarotta, 2010; Uusitalo et al. 2014(1)) have indicated that by using ORCs in recovering heat of different types of large-scale reciprocating engines, the power output can be increased about $9-12 \%$ depending on the type of the engine, operating conditions, and power scale.

Despite the large number of thermodynamic studies on using ORCs in different waste heat applications, there is very little detailed research available related to the environmental advantages of using ORC to produce electricity from waste heat. Poeschl et al. $(2010 ; 2012)$ have studied the efficiency and environmental impacts in various biogas production and utilization pathways, including a combined heat and power (CHP) power plant having an ORC as a bottoming cycle for recovering waste heat. Their results highlighted that the efficiency and the produced emissions in biogas utilization are highly dependent on the efficiency of the energy conversion system as well as on the potential substitution of the usage of different fossil fuels. Liu et al. (2013) have conducted detailed research on the environmental impacts of electricity production from low temperature waste heat using an ORC process. They have concentrated on emissions from the construction, utilization and decommissioning phases. In their study, seven different working fluids were considered and the effects of the working fluid on the emissions were analyzed. According to their life cycle assessment (LCA) results, the construction phase is the most important when GHG emissions are considered and the payback time for GHG emissions varies from three to six years, depending on the reference electricity production method. Yang and Yeh (2015) have concentrated on the thermodynamics and economics of the ORC process utilizing waste heat in large marine diesel engines. According to their study, the production of electricity with an ORC from the diesel engine exhaust gas instead of using diesel fuel led to a $76 \%$ reduction in $\mathrm{CO}_{2}$ emissions. Walsh and Thornley (2012 (2)) have studied the environmental impacts of using low grade heat for electricity production via ORC in the production of metallurgical coke. Their results showed the installation of ORC could offset 1 to $3 \%$ of the $\mathrm{CO}_{2}$ emitted directly through the production of coke. Furthermore, they concluded that the life-cycle environmental impacts of coke production would be reduced less than $1 \%$.

Despite the earlier studies, there is still lack knowledge related to the environmental impacts of using ORC in recovering exhaust gas heat of biogas engines. In addition to calculating GHG emissions for ORC, the electricity reference scenarios have to be carefully considered. There may be already heat utilization for gas engine exhaust gas, such as recovering the heat to the digester in biogas production, which may have effects on, GHG performance of the ORC process. In addition, there are various factors along the life cycle of electricity production with ORC that need to be studied in more detail. The utilization period of previous studies is mainly 20 years, which may be too optimistic for an ORC process. Liu et al. (2013) have included only steel parts in the construction of the ORC process despite the fact that various other materials are used.

The objective of this paper is to study GHG emission reduction potentials of the ORC process with biogas gas engines in different situations using life cycle assessment methods. The use and construction phases as well as production of working fluid are included in the current study. 


\section{Materials and method}

This chapters provides information on the calculation model for answering the research questions.

\subsection{Background}

In Europe, the majority of the installed ORC power plants are fueled with solid biomass (Colonna et al., 2015). There are also ORC systems in operation that are utilizing exhaust gas heat of different types and different power level diesel engines, including exhaust gas heat recovery from biogas engines (van Buijtenen et al., 2013). ORC systems that are directly fueled by biogas have also been proposed (Bove \& Lunghi, 2006). To the authors' knowledge, there is currently one ORC system utilizing exhaust heat of biogas engines in a landfill (Turboden, 2016), and one ORC unit utilizing exhaust heat of a sewage gas engine (Triogen, 2016) in Finland. Therefore, there is a substantial potential to increase the number of waste heat recovery systems in the existing biogas plants.

\subsection{Life cycle assessment methods and scenario setting}

Life cycle assessment (LCA) is a method developed for increasing understanding and addressing environmental impacts associated with different products (ISO 14040). The LCA includes impacts from cradle to grave not concentrating only on use or production processes. LCA is standardized by the International Organization for Standardization (ISO) with a publication series of the 14040 standards (GHG Protocol). According to Cherubini et al. (2009), the scientific community widely agrees that LCA is one of the best methodologies for the evaluation of the environmental burden by identifying energy and materials used as well as emissions related to the environment.

In this paper, LCA methods are applied to evaluate potential for GHG emissions reductions by using the ORC process to increase electricity production from gas engine waste heat. The evaluation is carried out by comparing two scenarios:

1) Scenario 1 where only electricity from a gas engine is utilized

2) Scenario 2 where electricity and heat from a gas engine are utilized

In both scenarios the following four cases were evaluated:

a. Additional electricity is produced using average methods

b. Additional electricity is produced using marginal methods

c. Additional electricity is produced using biogas

d. The ORC process is used

The scenarios include situations where all the produced heat is waste heat and where heat is utilized for example to heat digester. All heat from a gas engine can be considered as waste heat for example in dry digestion biogas plants that are utilizing heat from a compost plant (Labio Oy, 2016) or from other heat sources. In addition typically with landfill biogas engines there is no use for heat. Furthermore, there are various methods to produce electricity in cases which do not include ORC. 
The comparison is modeled using the system expansion method presented in ISO/TR 14049. In system expansion, similar amount of products is produced in different cases to enable fair comparison. Therefore, in this study a similar amount of electricity and heat has to be produced in all cases. Because with the ORC process more electricity is produced, in cases a-c additional electricity has to be produced using other electricity production methods. LCA modelling has been carried out using GaBi 6.0 software. Initial data for the model has been collected from literature and in some cases $\mathrm{GaBi}$ database values have been used. Data sources for each data selected for the model are mention later in the text. Figure 2 presents the system boundaries and differences between cases and scenarios chosen in this study.

CASES A-C: ELECTRICITY PRODUCTION FROM BIOGAS WITH GAS ENGINE

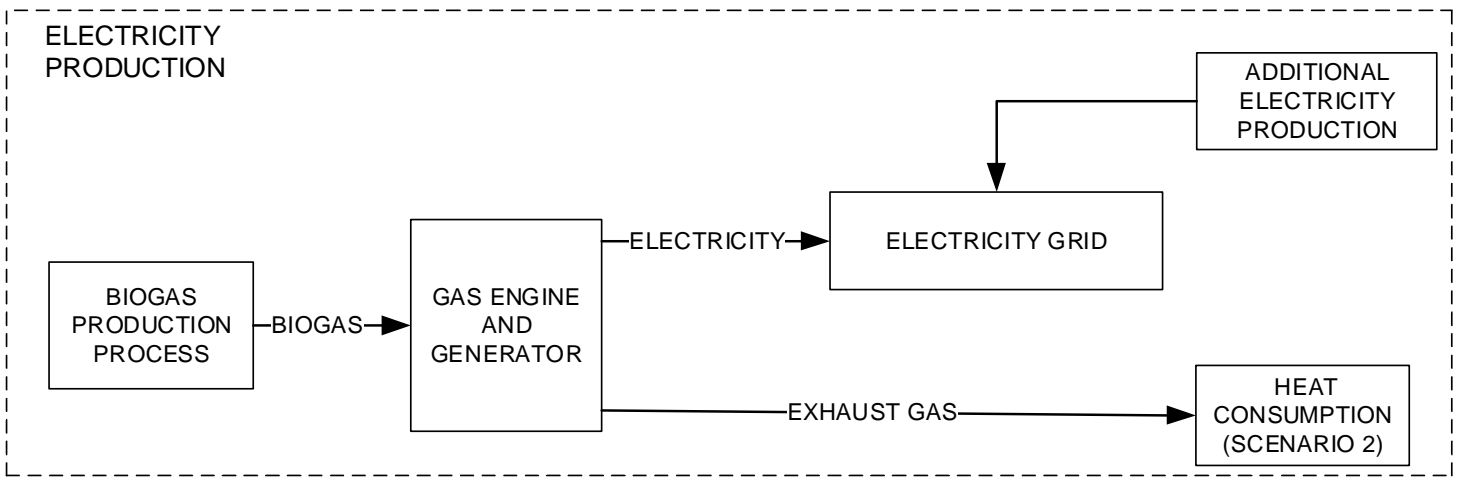

CASE D: ELECTRICITY PRODUCTION FROM BIOGAS WITH GAS ENGINE AND ORC PROCESS

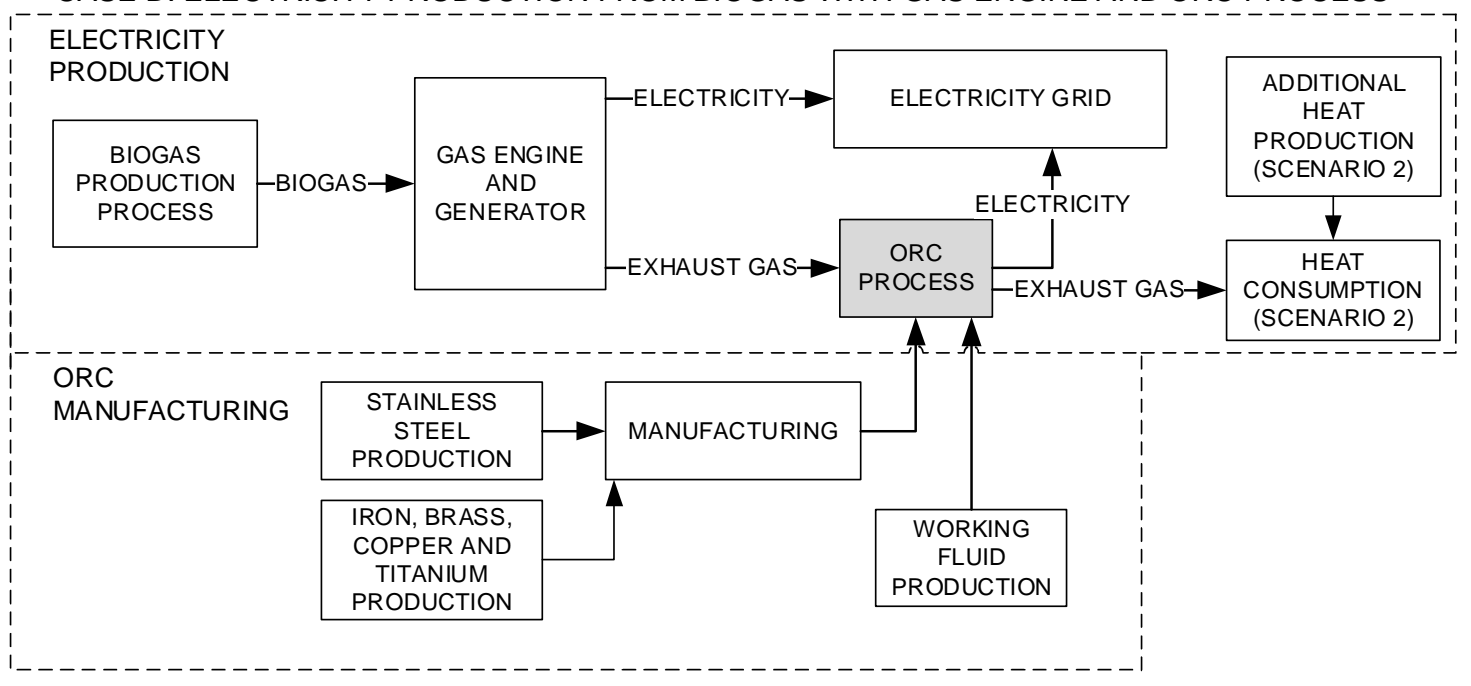

FIGURE 2. LCA scenarios, case settings and system boundaries for the calculation model.

\subsection{Assumptions and data collection}

An example gas engine in this study is Deutz Power Systems's TCG 2020 V12 biogas engine having an electrical power output of $1022 \mathrm{~kW}$. The electricity production efficiency is $41 \%$ and the annual operational period is assumed to be $7000 \mathrm{~h}$ (Deutz Power Systems). The minimum heating value for biogas is $5 \mathrm{kWh} \mathrm{m}^{-3}$ thus leading to the maximum $3500000 \mathrm{~m}^{3} / \mathrm{a}$ biogas consumption. This corresponds to gas production in medium sized Finnish biogas plants (Huttunen \& Kuittinen, 2013). Also a gas turbine could have been a possible option for electricity production from biogas, but the operation principle(electricity production) is similar 
to that of the gas engine and therefore the results can also be applied to other methods to obtain electricity from biogas. The main differences between the gas engine and gas turbine technologies are in the electricity conversion efficiency and in waste heat temperature levels and distribution.

In this study it was assumed that the installation of the ORC system to the exhaust pipe of the biogas engine does not have a significant effect on the power output or electric efficiency of the biogas engine. Similar assumption has been used in the previous studies considering the combination of a large scale engine and an ORC (Bombarda et al. 2010, Uusitalo et al. 2014(1)). Bei et al. (2015) studied the effect of the exhaust gas pressure drop caused by the ORC evaporator on the engine performance and they concluded that the engine power loss was less than $1 \%$ in all the studied cases.

The thermodynamic design and the estimated need for construction materials of the studied ORC were based on the information available on a commercial ORC system having an electric power output of $170 \mathrm{~kW}$ (van Buijtenen, 2009; van Buijtenen et al. 2013), as well as on the experience gained in the design and construction of different experimental ORC systems at LUT (van Buijtenen et al., 2003; Uusitalo 2014; Uusitalo et al., 2015). The studied ORC system uses toluene as the working fluid and includes a turbine-generator for expanding the working fluid vapor. Toluene can be classified as an aromatic hydrocarbon and it has been identified to represent high thermodynamic performances in high temperature ORC applications, such as in exhaust gas recovery (Branchini et al., 2013; Uusitalo et al., 2014(1); Costall et al., 2015) and can be thus considered as a suitable fluid for the studied application. In addition, ORC systems using turbines instead of other type of expanders are typically preferred in commercial hightemperature ORC applications, such as in exhaust gas recovery, at the power levels above 100 $\mathrm{kW}$ (Colonna et al. 2015). The studied ORC system was scaled down by using values of the commercial ORC system in order to match the exhaust gas values of the studied engine, since the need for the heat power of the selected commercial ORC unit is higher than the exhaust heat power available from the studied biogas engine. It was assumed that the scaling does not have a significant effect on the thermodynamic performance of the ORC cycle and thus, the electric efficiency and other thermodynamic parameters of the designed ORC were set to the same values as in the commercial $170 \mathrm{~kW}$ ORC.

The process design was carried out by using the thermodynamic library REFPROP (Lemmon et al. 2010) and the well-known calculation principles of the Rankine cycle. The main results of the ORC cycle design are presented in Table 1. Figure 3 shows the temperature change in the ORC evaporator on the working fluid side and on the exhaust gas side as a function of transferred thermal power from the exhaust gas to the working fluid. 
TABLE 1. Main technical specifications of the studied ORC process.

\begin{tabular}{|l|c|}
\hline Working fluid & Toluene \\
\hline Electric power output, $\mathrm{kW}$ & 111 \\
\hline Electric efficiency, \% & 21.3 \\
\hline Evaporator heat rate, $\mathrm{kW}$ & 521 \\
\hline Working fluid flow rate, $\mathrm{kg} / \mathrm{s}$ & 0.84 \\
\hline Turbine inlet temperature, ${ }^{\circ} \mathrm{C}$ & 324 \\
\hline Turbine inlet pressure, bar & 32.3 \\
\hline Condensing temperature, ${ }^{\circ} \mathrm{C}$ & 57.5 \\
\hline Exhaust gas temperature at the evaporator inlet, ${ }^{\circ} \mathrm{C}$ & 479 \\
\hline Exhaust gas temperature at the evaporator outlet, ${ }^{\circ} \mathrm{C}$ & 180 \\
\hline Exhaust gas mass flow rate, $\mathrm{kg} / \mathrm{s}$ & 1.6 \\
\hline
\end{tabular}

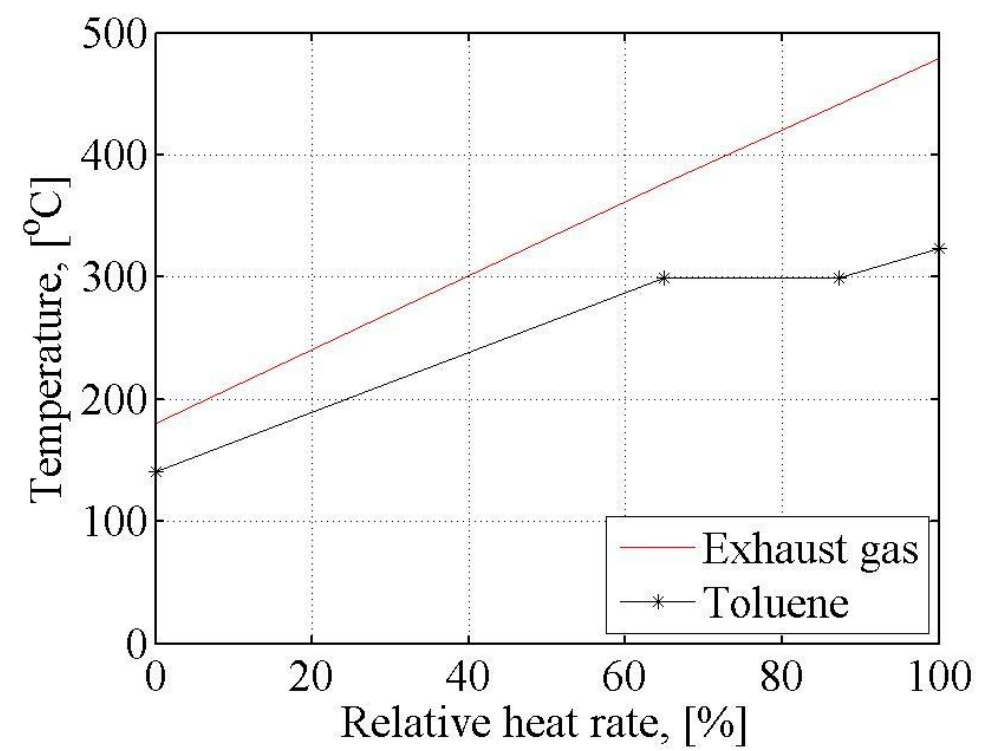

FIGURE 3. Exhaust gas and working fluid temperature profiles in the evaporator as a function of transferred thermal power from the exhaust gas to the working fluid.

The materials that are needed for the construction of the ORC plant were evaluated. The construction materials of the process heat exchangers, piping, and turbogenerator were taken into account in the analysis. The heat exchanger masses were evaluated based on the typical values of commercial plate and shell type of the heat exchangers. The evaporator was assumed to be a flow-through type allowing to have significantly lower amount of working fluid in the system, when compared to kettle type evaporators, but this type of evaporator requires a small degree of superheating of the organic vapor, in order to prevent droplets from entering the turbine. The materials needed for the power electronics and for the control and measurements of the system were excluded from the study since it was estimated that the construction of these components have only a minor effect on the GHG emissions, when compared to the other components of the process. The main results of the estimated materials are presented in Table 2. The amount of stainless steel is mainly used for the process piping and heat exchangers. The amount of iron, copper, brass, and titanium, as well as small portion of the stainless steel were estimated for the construction of the turbine-generator. 
TABLE 2. Estimated materials needed for the ORC construction.

\begin{tabular}{|l|c|}
\hline Material & Mass \\
\hline Stainless steel, kg & 4750 \\
\hline Iron, $\mathrm{kg}$ & 175 \\
\hline Brass, $\mathrm{kg}$ & 20 \\
\hline Copper, kg & 5 \\
\hline Titanium, kg & 25 \\
\hline Toluene, kg & 400 \\
\hline
\end{tabular}

The operating life of ORC devices is assumed to be 10 years and the environmental burden from manufacturing is divided between these years. There may be working fluid leakages in the process piping or through the expander sealing, and also working fluid decomposition might occur in the process, which would cause changes in the thermodynamic performance of the cycle over a long time period. The possible fluid decomposition can be caused by high peak temperatures of the cycle that can exceed the working fluid thermal stability threshold, especially if there are any impurities in the system (Erhart et al. 2015). Thus, the assumption was made that the working fluid is completely changed every second year. The leakages and decomposition of the working fluid can be lower than estimated in this study, but by choosing a high leakage rate, effects in the worst case can be revealed. A study by Larjola (1995), highlighted that ORC processes adopting high-speed turbines can be designed to be fully hermetic with no working fluid leakages.

Greenhouse gas emissions from biogas production and gas engines are similar in all cases. Therefore, GHG emissions from these process steps are modeled roughly. According to Uusitalo et al. (2014 (2)), GHG emissions from biogas production from biowaste are

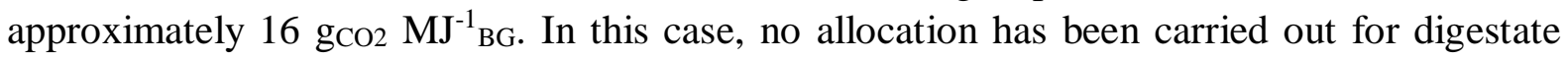
according to the calculation rules of directive 2009/28/EC. Also lower GHG factors for biogas have been presented in literature. According to directive 2009/28/EC, GHG emissions from biogas production and compression to $\mathrm{NG}$ grid pressure are typically $14 \mathrm{~g}_{\mathrm{CO} 2} \mathrm{MJ}^{-1} \mathrm{BG}$. Carbon dioxide $\left(\mathrm{CO}_{2}\right)$ emissions from gas engines are biogenic and are therefore excluded from this study (directive 2009/28/EC), but methane $\left(\mathrm{CH}_{4}\right)$ and nitrous oxide $\left(\mathrm{N}_{2} \mathrm{O}\right)$ are included. Emission factors for the gas engine utilized in this study are $0.323 \mathrm{~g}_{\mathrm{CH} 4} \mathrm{MJ}^{-1} \mathrm{BG}$ and $0.0005 \mathrm{~g}_{\mathrm{N} 2 \mathrm{O}}$ $\mathrm{MJ}^{-1}{ }_{\text {BG. }}$ (Nielsen et al., 2008). The ORC device and toluene production are modeled using $\mathrm{GaBi}$ 6.0 database processes for materials and for toluene leakages.

There are various options for additional electricity production methods in cases where ORC is not used. Differences in methods also lead to differences in GHG emissions. The highest GHG emissions are caused by using marginal electricity produced with coal. However, marginal electricity is not always produced by coal. During low electricity consumption hours, marginal electricity may also be produced for example by renewables. Replaced electricity is occasionally produced by coal, occasionally by renewables and mostly by other methods in between. Therefore, the average electricity production method could be the best assumption for additional electricity production. In this study, the chosen alternative electricity production methods are the average electricity production in EU-27, marginal electricity production using coal in Poland and renewable electricity production using biogas in Germany. Germany has been chosen to represent average EU biogas production because it is the largest biogas producer 
in the EU. Germany and Poland are leading coal consumers in the EU. In this study, electricity production from Polish coal is chosen as marginal electricity production technology (Europe's Energy Portal 2011). The emission factors between these assumptions vary greatly, but the sensitivity of the results can be studied. Electricity production from biogas has the lowest GHG factor. The GHG factor of the average electricity production is 1.3 times and marginal electricity 2.9 times higher than when the electricity is produced by using biogas as a fuel. Additional heat production is assumed to be carried out using EU-27 thermal energy production with NG. NG has been selected as the thermal energy production method because biogas production plants typically contain devices to produce heat from gaseous fuels. GHG emissions from additional electricity and heat production are modeled using $\mathrm{GaBi} 6.0$ database processes. The functional unit of the study is biogas produced at a biogas plant $\mathrm{MJ} \mathrm{a}^{-1}$.

\section{Results and discussions}

The results of the annual GHG missions from scenario 1 with different electricity production methods are presented in Figure 4.

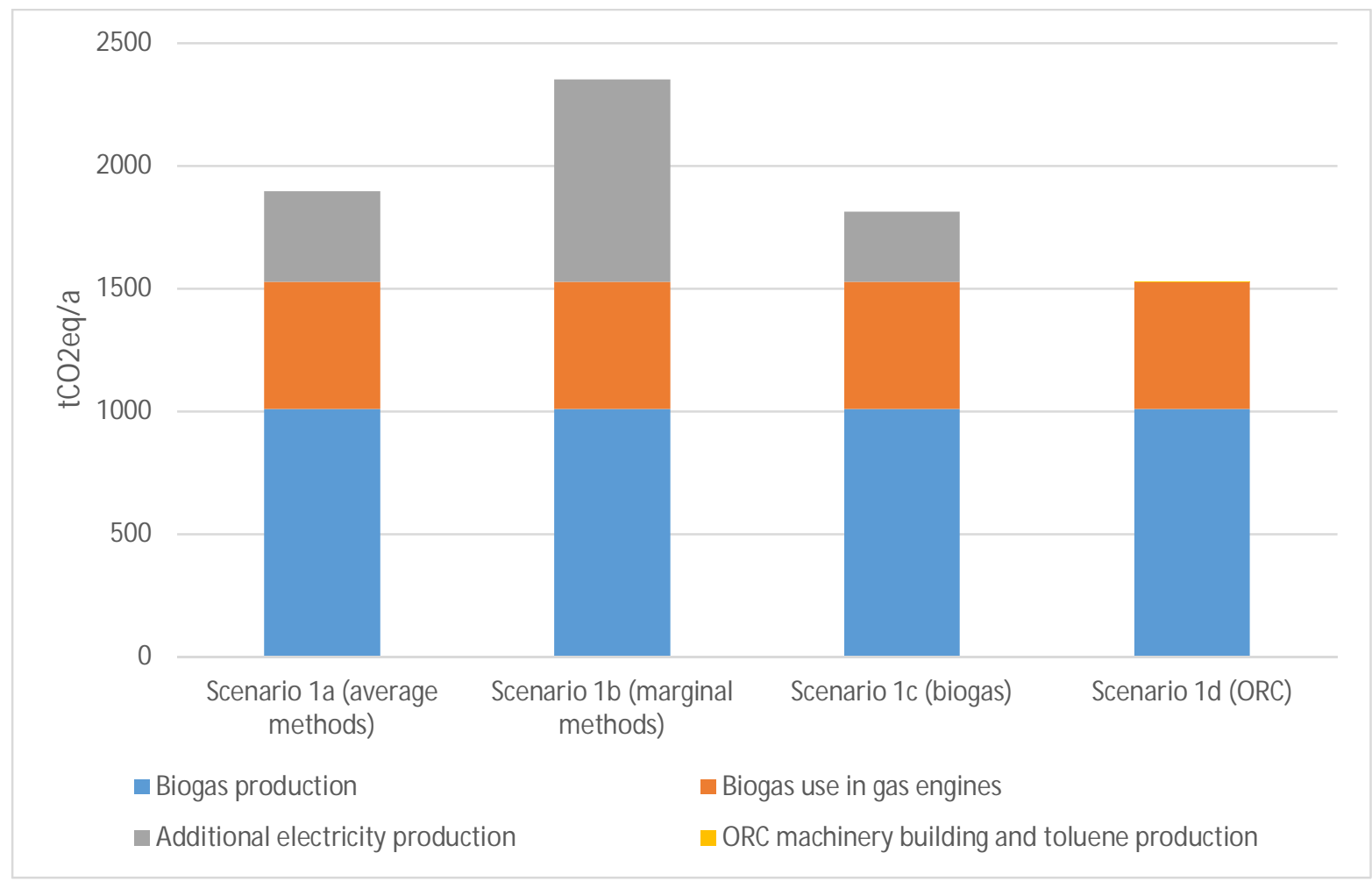

FIGURE 4 Annual GHG emissions from scenario 1 with different electricity production methods.

As can be seen in Figure 4, electricity production with ORC leads to lower GHG emissions than cases a-c where electricity has to be produced by other methods. With the inclusion of the ORC process into the system, the GHG emissions can be reduced by approximately 280-820 $\mathrm{tCO}_{2, \mathrm{eq}}(16-35 \%$ reduction) annually. The largest decrease in GHG emissions is obtained when ORC is used to replace marginal energy produced by coal and the lowest when it is used to replace electricity produced with biogas. However, average and marginal electricity production methods vary depending on the geographic location, and this study is carried out using EU values. In addition, the average and marginal electricity replacements are theoretical assumptions, and in reality, the method for additional electricity production varies over time. 
Nonetheless, the average and marginal electricity assumptions give information of boundaries where variations take place. In the case $d$ including the ORC, most significant GHG emissions are caused by the biogas production and operation of the gas engine. GHG emissions from toluene and ORC device production play only a marginal role in the results despite the fact that the working fluid in the system was assumed to be changed completely every second year. The ORC device and working fluid production lead only to $0.1 \%$ of the total GHG emissions of the biogas engine power plant in case $\mathrm{d}$.

Figure 5 shows how the GHG emissions are divided in the ORC machinery building and what the share of toluene production is in the comparison. The comparison is carried out assuming a ten-year utilization period and five toluene fillings. It shows that the stainless steel production had the highest effect on GHG emissions in ORC production and other materials have only a marginal effect from GHG perspective. The results indicate that only a 14-day utilization period for ORC is needed to compensate GHG emissions caused by ORC machinery construction and working fluid production if the average electricity production methods are replaced.

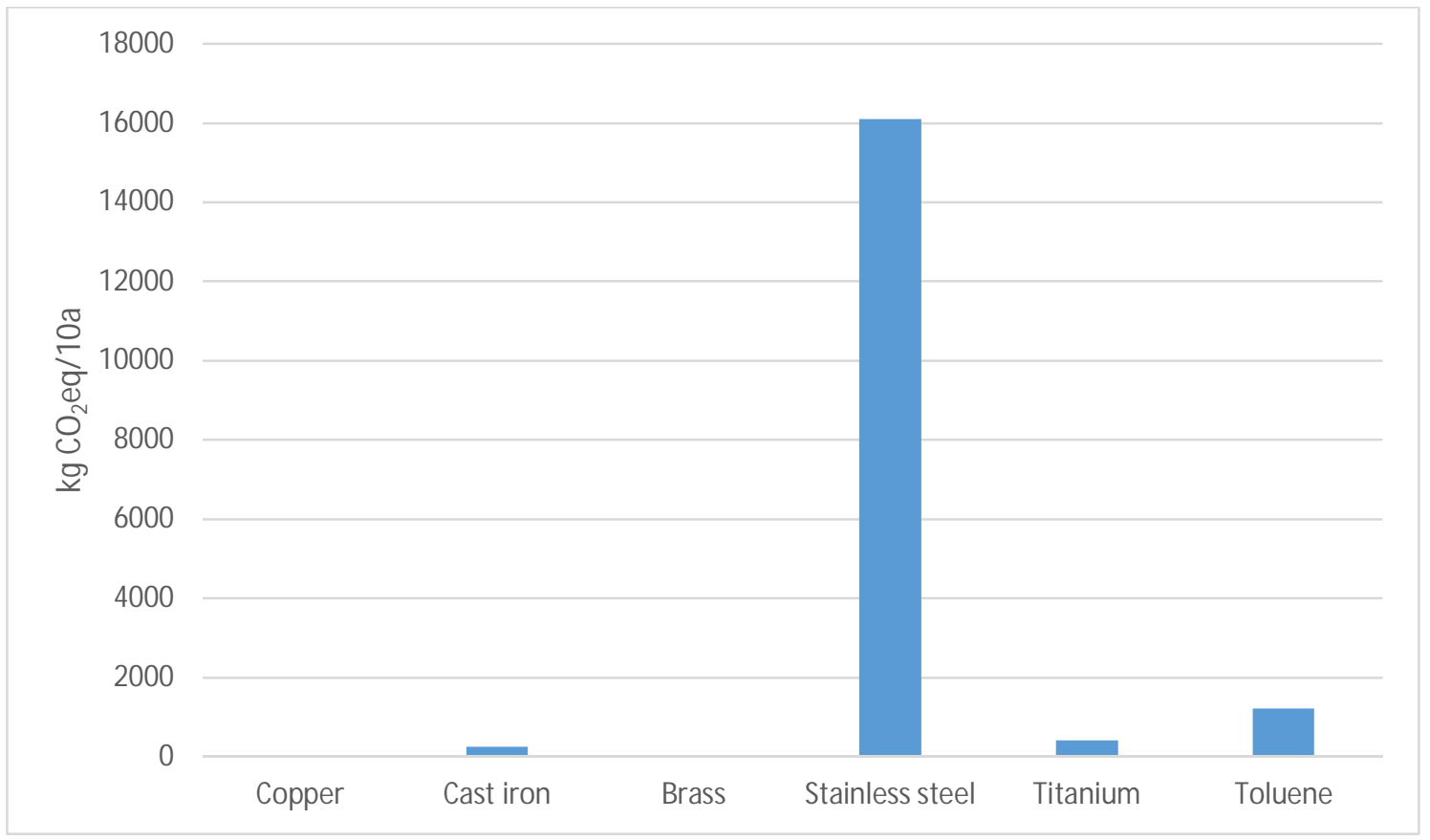

FIGURE 5 Annual GHG emissions from ORC machinery building and toluene production.

Figure 6 shows the annual GHG emissions in scenario 2 when the exhaust heat from a gas engine is used to heat the digester. In biogas digesters, the heat from engines can be utilized in heat digesters. Anaerobic digesters that are utilized for biogas production require low temperature heat to enable the digestion process. Mesophilic degradation takes place within the temperature range of $30-38^{\circ} \mathrm{C}$ and thermophilic degradation within temperature range $55-60^{\circ} \mathrm{C}$ (Tchobanoglous et al., 1993). The temperature levels in digesters are relatively low and therefore even low temperature waste heat can be used in heating processes. 


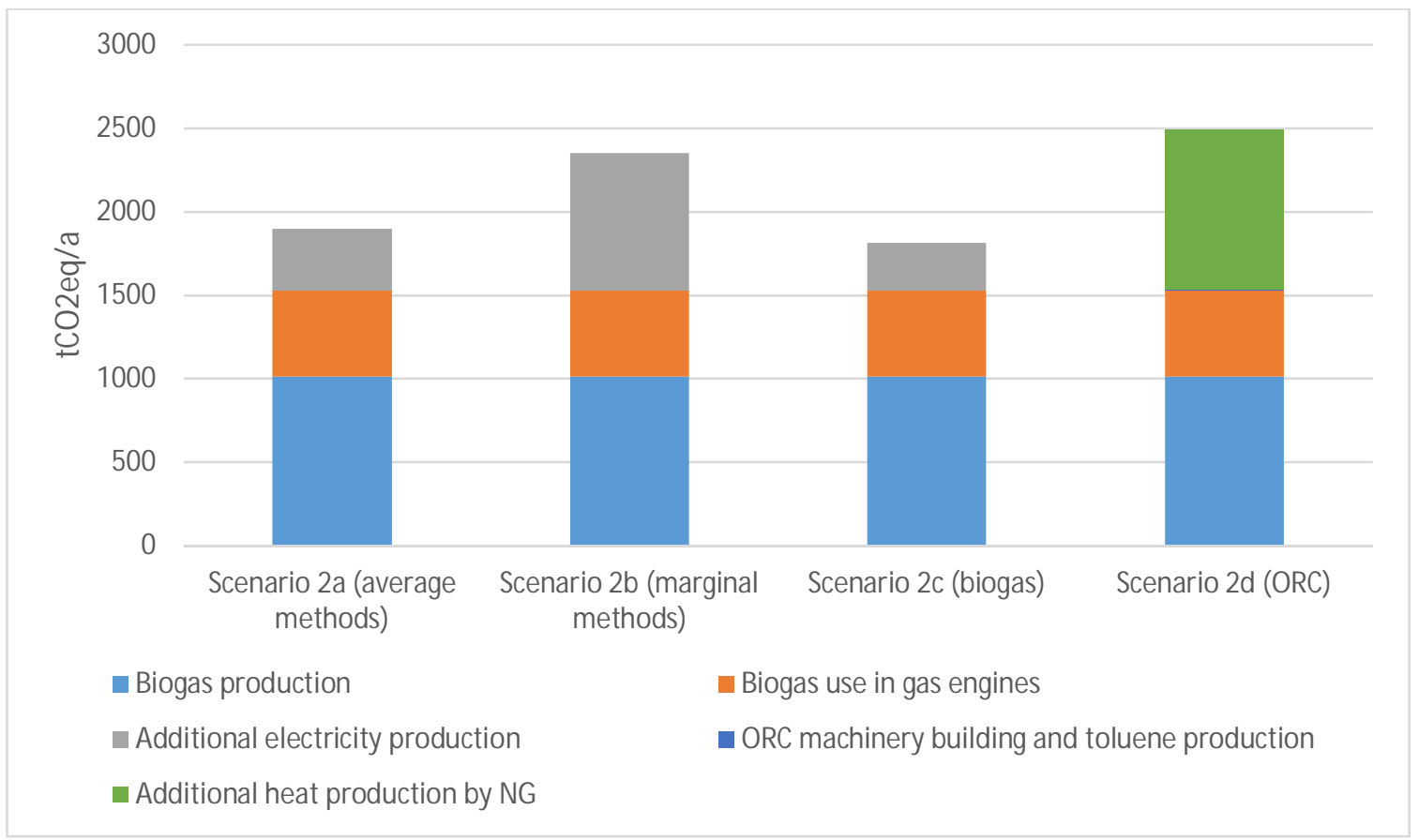

FIGURE 6 Annual GHG emissions from scenario 2 with different electricity production methods.

Figure 6 shows that if there is use for the exhaust gas heat produced in the gas engine power plant, it may not be advantageous from the GHG perspective to produce electricity from the exhaust gas heat with the ORC process. In these cases, additional heat has to be produced by using other methods, since the ORC uses part of the available heating power for producing additional electric power. In this analysis, the additional heat is assumed to be produced by using NG. However, if this additional heat can be produced by using biofuels such as woodchips instead of NG, GHG emissions from additional heat production would be lower. In scenario 2, a relatively high heat utilization rate is assumed for the biogas engine plant. In some cases, there might be use for only part of the exhaust heat as a heat power and in these cases there could be still sufficient amount of waste heat available for the ORC process without a need for producing significant amount of additional heat power by using other methods. In these cases, there could be potential for GHG emission reductions by using the ORC. It might be also possible to use the heat that is rejected in the ORC condenser for heating the digesters, especially if a relatively high condensing temperature would be adopted for the ORC process

Poeascl et al. (2012) have previously concluded that the potential substitution of the usage of different fossil fuels has a significant impact on ORC GHG results. These finding were confirmed. However, it is difficult to recognize the electricity production methods that are actually replaced and is always dependent on the case and geographical location. Liu et al. (2013), Yang and Yeh (2015) and Walsh and Thornely (2012 (2)) have all concluded that ORC use leads to GHG emission reductions. These findings were also confirmed with biogas engines. However, what was not previously pointed out is that biogas plants may have use for heat power and therefore GHG emission reductions are not obvious in every biogas engine plant. 


\section{Conclusions}

This paper examined the greenhouse gas emission reduction potential using the ORC process in recovering the exhaust gas heat of a biogas engine. The study focused on biogas engine power plants especially in Europe, and life cycle assessment was used to evaluate the environmental impacts of the use of ORC. The technical details of the studied ORC and the gas engine were based on the data available on a commercial ORC process and gas engine.

In the LCA evaluation, two scenarios and four cases in each scenario were studied. In the first scenario, the gas engine produced only electricity and all produced heat is considered as waste heat. In the second scenario, the exhaust heat from the gas engine is utilized as heat power. The four cases of the scenarios represent situations where the additional electricity is produced with four different ways: average methods, marginal methods, biogas or ORC. In the LCA, the production of the ORC process and working fluid were included. Furthermore, the working fluid leakage during the operation was taken into account. The following main findings were made:

- In the scenario where the exhaust heat is not utilized as heat power, the inclusion of ORC leads to lower GHG emissions. Depending on which type of electricity production is substituted with ORC, the annual GHG reduction is $280-820 \mathrm{tCO}_{2, \text { eq. }}$. The reduction of GHG is the lowest when ORC replaces electricity produced with biogas.

- Biogas production and operation of biogas engine have the most significant impact on total GHG emissions while ORC device and working fluid production constitute only $0.1 \%$ of total GHG emissions from biogas engine power plant.

- If all of the waste heat from the engine can be utilized the inclusion of ORC to produce additional electric power increases the total GHG emissions due to the need for additional heat production. However, if the additional heat is produced with e.g. biogas or woodchips instead of NG, the GHG emissions would be lower than presented in this paper.

It can be concluded that, from the point of view of GHG emissions, the benefit of using the ORC process in the studied biogas engine waste heat recovery depends on whether only electricity or also heat is to be produced. In addition, if the heat is already utilized the use rate plays a significant role when considering GHG emission reduction with ORC. However, the emissions due to the ORC building phase and working fluid production play almost a negligible role in the total GHG emissions of biogas engine power plant in all studied cases. Therefore, it may not be necessary to include these process steps in further ORC GHG studies. However, from other environmental perspectives these steps may be important and should be studied in the future. This paper gives an overview of GHG emission reduction potential of using ORCs in biogas engines. A similar approach can be taken to actual decision making when the use ORC and its advantages are considered and evaluated. The results show that ORC technology reduces GHG emissions and increases renewable electricity production from biogas engine waste heat. 


\section{Acknowledgements}

This project has been funded by the LUT Laboratory of Fluid Dynamics and LUT Laboratory of Environmental Technology. The authors would like to thank the reviewers for their valuable and constructive comments during the review process.

\section{References}

ASUE, 2006, Gasturbinen-Kenndaten-Referenzen. Available at http://asue.de/cms/upload/inhalte/gasturbinentechnik/broschuere/gasturbinenkenndaten_01.pd $\underline{\mathrm{f}}$

ASUE, 2011, BHKW-Kenndaten 2011. Available at http://asue.de/cms/upload/broschueren/2011/bhkw-kenndaten/asue-bhkw-kenndaten-0311.pdf

Bei, C., Zhang, H., Yang, F., Song, S., Wang, E., Liu, H., Chnag, Y., Wang H., and Yang, K. (2015). Performance Analysis of an Evaporator for a Diesel Engine-Organic Rankine Cycle (ORC) Combined System and Influence of Pressure Drop on the Diesel Engine Operating Characteristics. Energies, 8(6), 5488-5515.

Bombarda, P., Invernizzi, C.M., and Pietra, C. (2010). Heat recovery from Diesel engines: A thermodynamic comparison between Kalina and ORC cycles. Applied Thermal Engineering, 30(2-3), pp. 212-219.

Bove, R., and Lunghi, P., (2006). Electric Power Generation From Landfill Gas Using Traditional and Innovative Technologies," Energy Conversion and Management, 47(11-12), pp. 1391-1401.

Branchini, L., De Pascale, A., and Peretto, A. (2013). Systematic comparison of ORC configurations by means of comprehensive performance indexes. Applied Thermal Engineering, 61(2), 129-140.

Chacartegui, R., Sanchez, D., Munoz, J.M., and Sanchez, T. (2009). Alternative ORC bottoming cycles for combined cycle power plants. Applied Energy, 86(10), pp. 2162-2170.

Cherubini, F., Bird, N., D., Cowie, A., Jungmeier, G., Schlamadinger, B., Woess-Gallasch, S. (2009). Energy- and greenhouse gas-based LCA of biofuel and bioenergy systems: Key issues, ranges and recommendations. Resources, Conservation and Recycling, 53 (2009), pp. 434-447.

Colonna, P., Casati, E., Trapp, C., Mathijssen, T., Larjola, J., Turunen-Saaresti, T., and Uusitalo, A. (2015). Organic Rankine Cycle Power Systems: From the Concept to Current Technology, Applications, and an Outlook to the Future. Journal of Engineering for Gas Turbines and Power, 137(10), 100801.

Costall, A. W., Hernandez, A. G., Newton, P. J., and Martinez-Botas, R. F. (2015). Design methodology for radial turbo expanders in mobile organic Rankine cycle applications. Applied Energy, 157, 729-743. 
Erhart, T., Gölz, J., Eicker, U., and van den Broek, M. (2015). Fluid stability in large scale ORCs using siloxanes: long-term experiences and fluid recycling. Proceedings of 3rd International Seminar on ORC Power Systems, October 12-14, Brussels, Belgium.

Europe's Energy Portal. 2011. Coal consumption by country. Available at: https://www.energy.eu/stats/energy-coal-consumption.html

Huttunen, M., and Kuittinen, V. 2013. Suomen biokaasurekisteri n:o 17. Finnish biogas register number 17. Publication of the University of Eastern Finland. Available at: http://www.biokaasuyhdistys.net/media/Biokaasulaitosrekisteri2013.pdf

GaBi 6. Software-System and Databases for Life Cycle Engineering. PE International AG.

Greenhouse Gas Protocol. (2011). Product Life Cycle Accounting and Reporting Standards. GHG Protocol. World Resource Institute and World Business Council for Sustainable Development. ISBN 978-1-56973-773-6.

Invernizzi, C., Iora, P., and Silva, P. (2007). Bottoming micro-Rankine cycles for micro-gas turbines. Applied Thermal Engineering, 29, pp. 100-110.

ISO 14040. International Organization for Standardization. EN ISO 14040:2006. Environmental management. Life cycle assessment. Principles and framework.

ISO/TR 14049. International Organisation for Standardization. ISO/TR 14049:2000.

Environmental management, Life cycle assessment, Examples of application of ISO 14041 to goal and scope definition and inventory analysis.

Karvonen, M., Kapoor, R., Uusitalo, A., and Ojanen, V. (2015). Technology competition in internal combustion engine waste heat recovery: A patent landscape analysis. Journal of Cleaner Production, 112, pp. 3735-3743.

Labio Oy. (2016). Company website. [Accessed 18 February 2016]. Available at: http://www.labio.fi/en/enterprise-information/production-plants/

Larjola, J. (1995). Electricity from industrial waste heat using high-speed organic Rankine cycle (ORC). Int. J. Production Economics, 41, pp. 227-235

Liu, C., He, C., Gao, H., Xie, H., Li, Y., Wu, S., and Xu J. (2013). The environmental impact of organic Rankine cycle for waste heat recovery through life-cycle assessment. Energy, 56, pp.144-154.

Deutz Power Systems. TCG 2020 Technical data sheet.

Nielsen, O.-K. et al. 2008. Denmark's National Inventory Report 2008. Emission inventories 1990-2006. NERI Technical Report No. 667. Available at: http://www2.dmu.dk/Pub/FR667.pdf 
Poeschl, M., Ward, S., and Owende, P. (2010). Evaluation of energy efficiency of various biogas production and utilization pathways. Applied Energy, 87(11), pp. 3305-3321.

Poeschl, M., Ward, S., \& Owende, P. (2012). Environmental impacts of biogas deploymentPart I: life cycle inventory for evaluation of production process emissions to air. Journal of Cleaner Production, 24, pp.168-183.

Lemmon, E. W., Huber, M. L., \& McLinden, M. O. Refprop 9.0, NIST standard reference database 23, Version 9.02010.

Tchanche, B.F., Lambrinos, G., Frangoudakis, A., and Papadakis, G. (2011). Low-grade heat conversion into power using organic Rankine cycles-a review of various applications.

Renewable and Sustainable Energy Reviews, 15(8), pp. 3963-3979.

Tchobanoglous, G., Theisen, H., Vigil, S.A. (1993). Integrated Solid Waste Management. Engineering principles and management isuues. MCGraw-Hill International Editions. Civil Engineering Series 978 s. ISBN 0-07-112865-4.

Triogen, (2016), company website [Accessed 19 February 2016]. Available at: www.triogen.nl

Turboden s.r.l., (2016), company website [Accessed 19 February 2016]. Available at: www.turboden.eu

Uusitalo, A. (2014) Working fluid selection and design of small-scale waste heat recovery systems based on organic Rankine cycles. Doctoral Thesis, Lappeenranta University of Technology Acta Universitatis Lappeenrantaensis 615, Lappeenranta, ISBN 978-952-265710-7.

Uusitalo, A., Honkatukia, J., Turunen-Saaresti, T., and Larjola, J. (2014(1)). A Thermodynamic Analysis of Waste Heat Recovery from Reciprocating Engine Power Plants by means of Organic Rankine Cycles. Applied Thermal Engineering, 70(1), pp.33-41.

Uusitalo, V., Havukainen, J., Kapustina, V., Soukka, R., and Horttanainen, M. (2014 (2)). Greenhouse Gas Emissions of Biomethane for Transport: Uncertainties and Allocation Methods. Energy \& Fuels 28, pp.1901-1910.

Uusitalo, A., Honkatukia, J., Backman, J., and Nyyssönen, S. (2015). Experimental Study on Charge Air Heat Utilization of Large-Scale Reciprocating Engines by means of Organic Rankine Cycle. Applied Thermal Engineering, 89(1), pp. 209-219.

Vaja, I. and Gambarotta, A. (2010). Internal Combustion engine (ICE) bottoming with Organic Rankine Cycles (ORCs). Energy, 35(2), pp.1084-1093.

van Buijtenen, J.P., Larjola, J., Turunen-Saaresti, T., Honkatukia, J., Esa, H., and Backman, J. (2003). Design and validation of a new high expansion ratio radial turbine for ORC application. 5th European Conference on Turbomachinery, Prague, 17-22, March 2003. 
van Buijtenen, J.P. (2009). The Tri-O-Gen Organic Rankine Cycle: development and perspectives. Power Engineer, Journal of the IDGTE (The Institution of Diesel and Gas Turbine Engineers), 13(1).

van Buijtenen, J., Eppinga, Q., and Ganassin, S., (2013), "Development and Operation of a High Temperature High Speed Organic Rankine Cycle System," 2nd International Seminar on ORC Power Systems (ORC2013), Rotterdam, Oct. 7-8.

Walsh, C. and Thornley, P., (2012 (1)) "Barriers to improving energy efficiency within the process industries with a focus on low grade heat utilisation." Journal of Cleaner Production, 23.1, pp.138-146.

Walsh, C., and Thornley, P. (2012 (2)). The environmental impact and economic feasibility of introducing an Organic Rankine Cycle to recover low grade heat during the production of metallurgical coke. Journal of Cleaner Production, 34, pp.29-37.

World Resource Institute. (2009). World Greenhouse Gas Emissions: 2005 [online document]. [Accessed 27 December 2012]. Available at:

http://www.wri.org/publication/world-greenhouse-gas-emissions-2005

Yang, M. H., and Yeh, R. H. (2015). Thermodynamic and economic performances optimization of an organic Rankine cycle system utilizing exhaust gas of a large marine diesel engine. Applied Energy, 149, pp.1-12. 